\title{
Percepção de Alunos do Ensino Médio sobre Primeiros Socorros
}

\author{
Perception of High School students on First Aid \\ Percepción de los estudiantes de Secundaria sobre Primeros Auxilios
}

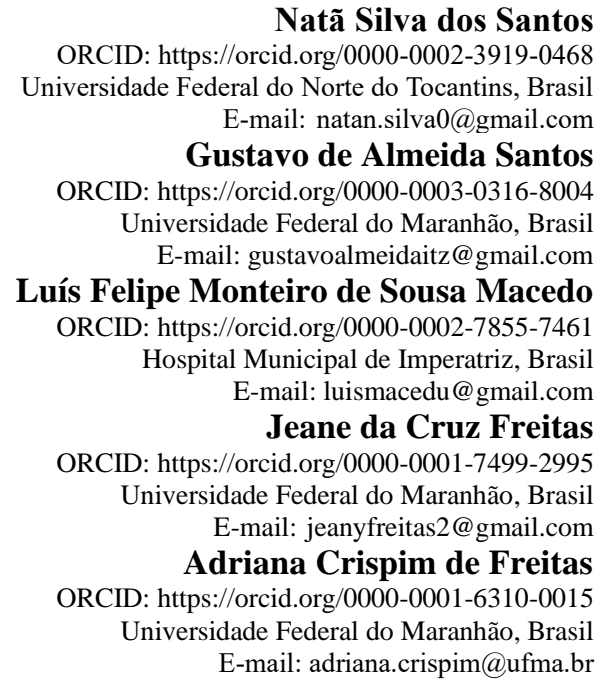

\section{Resumo}

O estudo teve como objetivo verificar o nível de conhecimento dos alunos do ensino médio de uma escola da rede pública acerca de primeiros socorros e suas reações mediante as necessidades de urgência e emergência. Método: tratase de um estudo transversal de natureza aplicada, com caráter quantitativo. Quanto aos fins da pesquisa caracteriza-se como descritiva, sendo a obtenção de dados realizada através da aplicação de um formulário aos estudantes do $1^{\circ}$ ao $3^{\circ}$ ano do Ensino Médio. Resultados: Participaram do estudo 167 alunos, de ambos os sexos, com idade variável entre 15 e 18 anos, sendo que desses $95 \%$ relataram que o ambiente escolar é sim propício a ocorrência de acidentes e que possam necessitar de assistência de primeiros socorros imediata, e ainda segundo esses 37,7\% já passaram por situações em que era necessária intervenção rápida, mas que nessas situações 50,2\% não sabia o que fazer. Conclusão: Foi possível perceber a importância da capacitação desses alunos a respeito de primeiros socorros, tendo em vista o ambiente o qual os mesmos estão expostos todos os dias e como esses conhecimentos podem ser eficazes e crucias diante de situações de pessoas vítimas de circunstância emergenciais.

Palavras-chave: Ambiente escolar; Educação em saúde; Urgência e emergência.

\begin{abstract}
The study aimed to verify the level of knowledge of high school students in a public school about first aid and their reactions to the needs of urgency and emergency. Method: this is a cross-sectional study of an applied nature, with a quantitative character. As for the purposes of the research, it is characterized as descriptive, with data being obtained through the application of a form to students from the 1st to the 3rd year of high school. Results: The study included 167 students, of both sexes, aged between 15 and 18 years old, of whom 95\% reported that the school environment is indeed conducive to the occurrence of accidents and that they may need immediate first aid assistance, and according to these $37.7 \%$, they have already gone through situations in which rapid intervention was necessary, but in these situations $50.2 \%$ did not know what to do. Conclusion: It was possible to realize the importance of training these students regarding first aid, in view of the environment to which they are exposed every day and how this knowledge can be effective and crucial in the face of situations of people who are victims of emergency circumstances.
\end{abstract}

Keywords: School environment; Health education; Urgency and emergency.

\section{Resumen}

El estudiotuvo como objetivo verificar elnivel de conocimiento de losestudiantes de secundaria en una escuela pública sobre primerosauxilios y sus reacciones ante lasnecesidades de urgencia y emergencia. Método: se trata de unestudio transversal de carácter aplicado, de carácter cuantitativo. Encuanto a los fines de lainvestigación, se caracteriza por ser descriptivo, siendolosdatosobtenidos mediante laaplicación de unformulario a losestudiantes de $1^{\circ}$ a $3^{\circ}$ de bachillerato. Resultados: El estudioincluyó a 167 estudiantes, de ambos sexos, conedadescomprendidas entre los 15 y los 18 años, 
de loscualesel 95\% informó que el ambiente escolar es propicio para laocurrencia de accidentes y que puedennecesitarprimerosauxiliosinmediatos, y aúnasí, de acuerdo. de este 37,7\% yahapasado por situacionesenlas que era necesaria una intervención rápida, pero en estas situacionesel 50,2\% no sabíaquéhacer. Conclusión: se pudo dar cuenta de laimportancia de capacitar a estosestudiantesenprimerosauxilios, en vista del entorno al que estánexpuestos cada día y cómo este conocimientopuede ser efectivo y crucial ante situaciones de personas que sonvíctimas de emergencia circunstancias.

Palabras clave: Entorno escolar; Educación para lasalud; Urgencia y emergência.

\section{Introdução}

O ambiente escolar é um local em que crianças e adolescentes tem seus primeiros contatos sociais, sendo esse ambiente organizado e estruturado para orientar na formação pessoal e social desses, que estudam desde números, cálculos e formulas até teorias filosóficas e sociais que norteiam a formação do caráter crítico e a percepção dessas crianças e adolescentes quanto ao mundo que nos cerca. No entanto, assim como em outros ambientes sociais, a escola também apresenta riscos para todos os que a frequentam, principalmente para crianças e adolescentes que estão mais propícios a acidentes devido, na maioria das vezes, ao seu grande número de alunos interagindo e desenvolvendo as mais diversas atividades motoras e esportivas (Lima \& Neves Junior, 2016; Galindo Neto, 2017).

Os primeiros socorros são práticas e procedimentos emergenciais realizados em pessoas vítimas de algum acidente, ferida, inconsciente ou em perigo de vida, antes do início do atendimento de um profissional de saúde, com o objetivo de manter os sinais vitais e garantir a vida, podendo o socorro inicial ser feito por qualquer pessoa, todavia, para realização de tal deve ter ciência de como manusear as técnicas, quando e o tempo de ação e pausa (Filho et al.,2015).

De acordo com De Buck (2015), as pessoas que presenciam um acidente, lesão, doença súbita e/ou outra situação que necessite de socorros imediatos podem desempenhar, quando realizados da forma correto, um papel vital salvando vidas e diminuindo danos provocados pela situação como um todo. Segundo o estudo de Banfai (2017), a aplicação da educação em primeiros socorros a partir da primeira série da escola primária (7 anos) deve ser obrigatória, uma vez que mesmo com muitas limitações, crianças a partir dessa idade, quando ensinadas e treinadas corretamente, são capazes de aprender atividades básicas de primeiros socorros, incluindo ligar para o serviço de ambulância, iniciar a Ressuscitação Cardiopulmonar, usar um Desfibrilador Externo Automático, lidar com um paciente inconsciente e controlar sangramentos graves, levando em consideração que muitas pessoas que necessitam de assistência médica em situações de emergência morrem porque os primeiros socorros não são realizados.

Apesar dos muitos benefícios que podem ser relacionados pela realização de primeiros socorros de forma imediata e adequados, também é necessário pontuar o quão comprometedor pode ser esses quando realizados de forma inadequada, provocando inclusive sequelas irreversíveis e até a morte da vítima em algumas situações, sendo nesse sentido de grande relevância a capacitação do público de forma geral quanto à prestação de primeiros socorros (Oliveira et al., 2013).

No estado do Rio de Janeiro, a Assembleia Legislativa aprovou o projeto de Lei ${ }^{\circ} 1.689$ de 07 de agosto de 2012, e no artigo $2^{\circ}$ incisos I e II relata sobre Programas de Lições de Primeiros Socorros que proporciona o aprendizado aos professores e aos alunos noções de como lidar com situações de urgência e emergência que exijam mediações rápidas para as práticas de primeiros socorros na ocorrência de acidentes. O Ministério da Saúde, por outro lado, por meio da Política Nacional de Atenção as Urgências em sua Portaria $\mathrm{N}^{\circ} 1.863 / \mathrm{GM}$ art. $2^{\circ}$ inciso III, estimula estratégias promocionais da qualidade de vida e saúde capazes de prevenir agravos, proteger a vida, educar para a defesa da saúde e recuperar a saúde, protegendo e desenvolvendo a autonomia e a equidade de indivíduos e coletividades.

Em 4 de outubro de 2018 foi sancionada a Lei $N^{\circ}$ 13.722, que torna obrigatória a capacitação em noções básicas de primeiros socorros de professores e funcionários de estabelecimentos de ensino públicos e privados de educação básica e de 
estabelecimentos de recreação infantil, e ela surgiu após a morte de um menino de 10 anos vítima de engasgo em uma excursão escolar e que não recebeu os primeiros socorros. Nesse sentido, a falta de conhecimento e treinamento da população acerca de primeiros socorros traz impactos diretos nas taxas de sobrevivência das vítimas, haja vista que em situações em que são necessários cuidados imediatos, os mesmos não são realizados (Matos, Souza \& Alves, 2016).

A escola, além do papel fundamental na formação de crianças e adolescentes, pode atuar também como fonte de conhecimentos que podem salvar vida de pessoas que frequentam a própria escola, assim como de familiares, amigos e vizinhos dos estudantes. Nesse contexto, este estudo objetiva verificar o nível de conhecimento dos alunos de uma escola da rede pública, sobre os princípios básicos dos primeiros socorros e suas reações mediante as necessidades de urgência e emergência.

\section{Metodologia}

Trata-se de um estudo transversal de natureza aplicada, com caráter quantitativo. Segundo Pereira A. S. et al. (2018), a pesquisa quantitativa tem um caráter estatístico, uma vez que os números resultantes da coleta de dados geram dados matemáticos que podem ser analisados em forma de porcentagens, probabilidades, métodos analíticos e dentre outros. Quanto aos fins da pesquisa, caracteriza-se como descritiva, pois tem como objetivo primordial a exposição de características de uma determinada população. A pesquisa foi realizada em uma escola estadual no estado do Maranhão.

No que se referem aos preceitos éticos, os participantes da pesquisa foram esclarecidos sobre os propósitos do estudo e deram seu consentimento por meio da assinatura do Termo de Assentimento Livre e Esclarecido (TALE) dos pais ou responsável legal e o Termo de Compromisso Livre e Esclarecido (TCLE), conforme preconiza a Resolução 466/2012 do Conselho Nacional de Saúde.

A amostra foi obtida por conveniência a partir da procura dos indivíduos em seus respectivos locais de estudo. Como critérios de inclusão foram utilizados, a saber: capacidade dos sujeitos de responder ao questionário integralmente, assinatura do TALE pelos alunos e TCLE pelos pais ou responsáveis legais, independentemente de cor/raça, credo e condição de saúde. A proposta de estudo foi composta conforme os seguintes critérios de elegibilidade: 1) ser aluno do ensino médio da rede estadual de educação que tenham idade superior a 14 anos; 2) assentir por escrito e ter por consentimento do responsável legal.

A escola possuía quatorze turmas do $1^{\circ}$ ao $3^{\circ}$ ano do ensino médio no turno matutino e vespertino em 2017 , totalizando 538 alunos. Para cálculo amostral o nível de confiança empregado foi de 95,0\%, erro amostral de 6,0\%. Sendo o tamanho da amostra de 179. Entretanto, devido à desistência e a não assinatura do TALE pelos alunos e do TCLE pelos pais, a amostra final foi de 167 alunos.

A coleta de dados foi realizada a partir de um formulário proposto pelos pesquisadores envolvidos na pesquisa, sendo realizado de forma coletiva com todos os participantes que foram questionados acerca do seu conhecimento sobre primeiros socorros e sobre o que fazer mediante as situações em que é necessária a prestação de socorros, sendo enfatizado que a pesquisa não era obrigatória e que a qualquer momento o aluno poderia desistir da pesquisa sem qualquer prejuízo para o mesmo. Além disso, todos os dados foram coletados exclusivamente para fins acadêmicos, não sendo em nenhum momento os participantes identificados. Os dados foram tabulados no programa de planilhas eletrônicas do Microsoft Office Excel, versão 2016, o qual consistiu na tabulação de todas as perguntas e respostas dos adolescentes, mostrando os resultados em gráficos e de forma descritiva.

\section{Resultados}

Participaram do estudo 167 alunos do ensino médio, sendo o segundo ano com o maior número de alunos participantes com percentual de $40 \%(n=66)$ seguido do primeiro ano com $37 \%(n=62)$ e o terceiro ano com $23 \%$ ( $n=39)$. Em relação ao perfil 
dos sujeitos, verificou-se predomínio do sexo feminino com 71,2\% dos participantes, o qual o público estudantil tinha idade entre 15 e 18 anos.

A Tabela 1 apresenta a reação dos participantes quanto à capacidade de prestar socorro a alguém machucado e se já vivenciaram uma situação em que não sabiam o que fazer.

Tabela 1: Participantes que seriam capazes de prestar socorro a alguém machucado e que já vivenciaram uma situação em que não sabiam o que fazer.

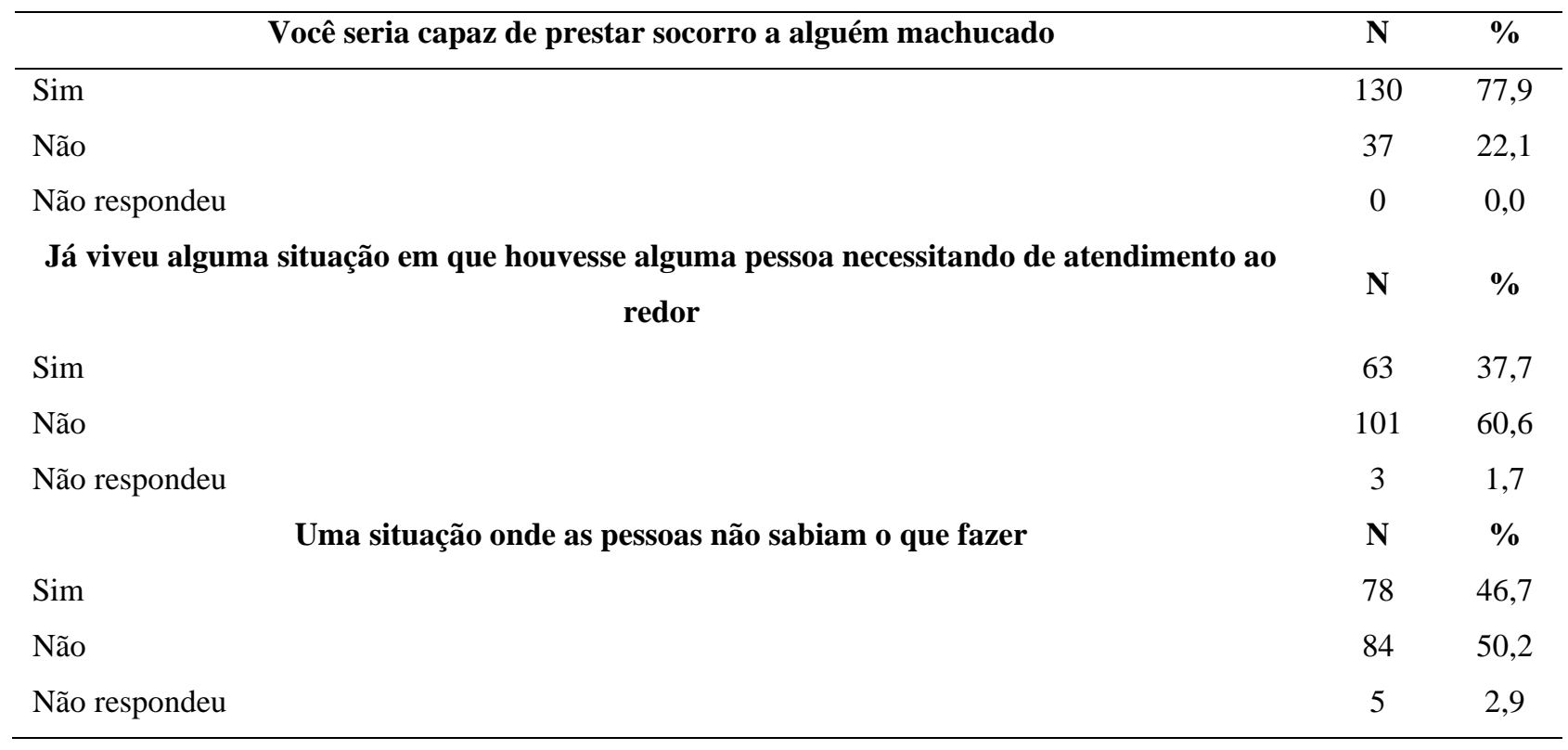

Fonte: Autores.

Os alunos foram questionados sobre a sua capacidade de prestar socorro a alguém machucado e se já vivenciaram uma situação em que não sabiam o que fazer. Percebeu-se que, 78,1\% (n=130) relataram ser capazes, enquanto apenas $22,1 \%(\mathrm{n}=37)$ afirmaram que não. Além disso, foram indagados se já haviam vivenciado alguma situação em que alguém ao redor tivesse necessitado de ajuda, 60,6\% (n=101) não presenciou, 37,7\% $(n=63)$ afirmaram que já presenciaram e 1,7\% (n=3) não respondeu ou não soube responder. Quando questionados sobre a vivência em uma situação em que as pessoas não sabiam o que fazer, $50,2 \%$ ( $\mathrm{n}=84$ ) não presenciaram situações de desconhecimento em relação a intervenção de primeiros socorros, enquanto 46,7\% $(n=78)$ estiveram presente em situações onde as pessoas não sabiam o que fazer e 2,9\% (n=5) não respondeu ou não soube responder.

Para representar a percepção dos alunos sobre os acidentes e se podem ser evitados ou podem acontecer nas escolas de ensino médio foi construído a Tabela 2. 
Tabela 2: Percepção dos alunos sobre os acidentes e se podem ser evitados ou acontecer em escolas de ensino médio

\begin{tabular}{|c|c|c|c|}
\hline & Você acredita que os acidentes podem ser evitados & $\mathbf{N}$ & $\%$ \\
\hline Sim & & 147 & 80,0 \\
\hline Não & & 19 & 18,0 \\
\hline Não respondeu & & 3 & 2,0 \\
\hline Total & & 167 & 100,0 \\
\hline & Os acidentes podem acontecer na escola de ensino médio & $\mathbf{N}$ & $\%$ \\
\hline Sim & & 158 & 95 \\
\hline Não & & 7 & 4,2 \\
\hline Não respondeu & & 1 & 0,8 \\
\hline Total & & 167 & 100,0 \\
\hline
\end{tabular}

Fonte: Autores.

Para quantificar a percepção dos alunos sobre os acidentes, se podem ser evitados ou podem ocorrer no ambiente escolar, mostrou que $80 \%(n=147)$ dos entrevistados concordam que os acidentes podem sim ser evitados, no entanto, 18\% (n=19) não acreditam na possibilidade de os acidentes serem evitados e apenas $2 \%(n=3)$ não respondeu ou não soube responder. Os participantes foram interrogados quanto à possibilidade de os acidentes acontecerem nas escolas do ensino médio, 95\% ( $\mathrm{n}=158$ ) acreditam que os acidentes podem acontecer no ambiente escolar, 4,2 (n=7) discordam e afirmam que não existe essa possibilidade de acidentes e $0,8 \%(n=1)$ não respondeu ou não soube responder.

Quando questionados sobre as pessoas que melhores são capacitadas para realizarem atividades de prevenção nas escolas, 36,5\% (n=61) falaram que outros profissionais são mais adequados a prevenção de acidentes, 29,3\% (n=49) afirmaram que todos os professores são capacitados, enquanto 17,5\% (n=29) relataram que o professor de educação física é o mais capacitado, 5,2 ( $\mathrm{n=8}$ ) dos alunos declaram que os professores de ciências são capazes de atender a urgências, 5,2 (n=8) acreditam que os demais funcionários conseguem intervir em ações de emergências, apenas 2,3\% (n=3) acreditam que os diretores são capazes de prestar atendimento, e 4\% $(n=6)$ não responderam ou não souberam responder. Quando questionados se a educação em saúde é um método de prevenção dos acidentes, 88,0\% (n=147) afirmaram que sim, que acreditam que a educação em saúde pode ser uma medida para se evitar acidentes e 7,8 (n=13) não consideram a ação em saúde como medidas profiláticas, 4,2 (n=9) não responderam ou não souberam responder.

A Tabela 3 apresenta a ocorrência e frequência de acidentes na escola, tipo de acidente e ocorrência de atividade de prevenção na escola. 
Tabela 3. Ocorrência e frequência de acidentes na escola, tipo de acidente e ocorrência de atividade de prevenção na escola.

\begin{tabular}{|c|c|c|}
\hline Em sua Escola, já ocorreram acidentes com algum aluno & $\mathbf{N}$ & $\%$ \\
\hline Sim & 43 & 25,7 \\
\hline Não & 93 & 55,3 \\
\hline Não responderam & 32 & 19,0 \\
\hline Quais foram os tipos de acidentes? & $\mathbf{N}$ & $\%$ \\
\hline Automobilístico & 4 & 2,4 \\
\hline Causas estranhas & 12 & 7,9 \\
\hline Queda & 12 & 7,9 \\
\hline Perfuração por arma branca & 1 & 0,6 \\
\hline Não ocorreu & 138 & 81,2 \\
\hline Frequência dos acidentes & $\mathbf{N}$ & $\%$ \\
\hline Diariamente & 12 & 8,0 \\
\hline 1 a 2 vezes por semana & 5 & 3,0 \\
\hline Quinzenalmente & 5 & 3,0 \\
\hline Outra frequência & 30 & 18,0 \\
\hline Não ocorreu & 115 & 68,0 \\
\hline
\end{tabular}

Fonte: Autores.

Os entrevistados foram interrogados quanto à ocorrência de acidentes com alunos no ambiente escolar, onde 25,7\% ( $n=43$ ) deram resposta afirmativa, 55,3\% ( $n=93$ ) relataram não ter ocorrido acidentes na escola e 19\% (n=32) não responderam ou não souberam responder. Quanto aos tipos de acidentes, 81,2\% (n=138) afirmaram não ter casos de acidentes na escola, no entanto, acidentes provenientes de quedas como aqueles que acontecem por causas estranhas ou desconhecidas (tropeços e engasgo) foram de 7,9\% ( $\mathrm{n}=12)$ cada. Ademais 2,4\% ( $\mathrm{n}=4)$ declaram que já ocorreram acidentes automobilísticos e 0,6\% ( $\mathrm{n}=1)$ relatou que o acidente foi ocasionado por arma branca.

Em relação às frequências de acidentes, na escola, $68 \%(n=115)$ dos participantes não responderam, devido ao fato de não ter presenciado acidentes, entretanto, $8 \%(\mathrm{n}=12)$ relataram que os acidentes ocorrem diariamente, $3 \%(\mathrm{n}=5)$ declaram que os acidentes ocorrem de uma a duas vezes por semana, $3 \%(\mathrm{n}=5)$ relataram ocorrer quinzenalmente e 18\% $(\mathrm{n}=30)$ declararam outra frequência (semestralmente, anualmente). Sobre o local de acontecimentos dos acidentes, 70,6\% ( $\mathrm{n}=118$ ) declararam não ter acidentes na área escolar e os acidentes que ocorreram 9,4\% ( $\mathrm{n}=16)$ foram no pátio, $9 \%(\mathrm{n}=15)$, na sala, 3\% ( $\mathrm{n}=5)$ na quadra, $2 \%(n=3)$ nos corredores e $6 \%(n=10)$ em outros ambientes escolares.

Os alunos foram questionados sobre a ocorrência de atividades de prevenção na escola, 65,2\% (n=109) declaram não terem ocorrido atividades de prevenção, $32,3 \%(\mathrm{n}=54)$ dos alunos afirmaram não existir atividade de prevenção e apenas $2,4 \%$ $(\mathrm{n}=4)$ admitiram a realização de atividades preventivas. 


\section{Discussão}

Almondes e Both (2013) afirmaram que em muitos casos relacionados ao atendimento de primeiros socorros, pode-se observar que as pessoas inseridas no ambiente escolar possuem pouco ou nenhum conhecimento técnico sobre o assunto, apesar de reconhecerem a necessidade de tê-lo. Logo, tal afirmação constata com os resultados encontrados, já que 77,9\% (n=130) dos participantes relataram ser capaz de prestar socorro a alguém machucado mesmo sem o conhecimento técnico especifico para prestação de socorro. Nessa perspectiva, orientar e capacitar a população para situações voltadas a emergências é extremamente necessário e devem ser mais difundidas em ambientes coletivos como escolas, empresas, academias e parques (Silva, 2011).

Apesar do questionamento quanto à vivência em situações onde havia pessoas necessitando de atendimento, 60,6\% $(n=101)$ responderam não ter presenciado tais situações, porém, 46,7\% (n=78) declararam que já presenciaram situações as quais pessoas não sabiam o que fazer, e apesar disso, para a prestação dos primeiros socorros não é necessário a presença de profissionais capacitados, pois esses cuidados podem ser oferecidos por indivíduos leigos. Contudo, para realizar um atendimento qualificado, a população necessita de conhecimentos suficientes e adequados sobre noções de primeiros socorros, o qual não acontece, sendo de suma importância a orientação de todos estabelecendo um elemento estratégico para diminuir a mortalidade e morbidade ocasionadas por acidentes e emergências (Dixe \& Gomes, 2015).

De acordo com os dados colhidos, 95\% $(\mathrm{n}=158)$ dos entrevistados acreditam que a área escolar pode ocorrer acidentes, onde muitas pausas entre as aulas ou o horário de intervalo para lanche representam um momento de tempo livre e, em geral, os alunos aproveitam para correrem e brincarem. Em consequência, muitas das vezes essas atividades provocam acidentes que podem deixar sequelas irreversíveis caso não tenham o atendimento adequado (leite et al., 2013). Por outro lado, 80\% (n=147) dos participantes concordam que os acidentes podem sim ser evitados no ambiente escolar. Segundo Silva et al. (2017), o conhecimento sobre os principais causadores e consequências de acidentes escolares podem contribuir para a sua diminuição e facilitar a execução de medidas mais específicas e efetivas na prevenção de tais fatores.

Cerca de 36,5\% (n=61) dos alunos relataram que outros profissionais, sobretudo os da área da saúde, são mais capacitados a prestar socorros que os professores, tendo em vista que 29,3\% (n=49) relataram que todos os professores são capacitados, enquanto $16,1 \%(n=27)$ e 5,2\% $(n=7)$ relataram que o professor de educação física e os de ciências são os mais capacitados. Leite et al., (2013) afirma que no espaço escolar, os acidentes constituem preocupação constante, sendo fundamental que os professores e aqueles que cuidam das crianças saibam como agir frente a esses eventos, como evitá-los e como realizar os primeiros socorros, procurando, assim, evitar as complicações decorrentes de procedimentos inadequados, o que pode garantir a melhor evolução e prognóstico das lesões.

Silva et al., (2015) afirma que os acidentes acontecem em todos os lugares, esses conhecimentos sobre primeiros socorros devem ser de domínio público visto que há diversas situações onde é exigido uma assistência imediata e qualificada. Para isso, torna-se imprescindível as práticas de educação em saúde no ambiente escolar, visto que ela permite que o aluno tenha autonomia e amplie sua visão sobre determinado assunto com o objetivo de prevenir e promover saúde Piantino, et al., (2018). Logo, 88,0\% (n=147) dos alunos afirmam que a educação em saúde pode ser uma medida para se evitar acidentes denotando a necessidade das práticas de urgência e emergência.

A sala de aula, portanto, não está livre de acontecer acidentes, aparece como cenário de consideráveis números de acidentes na escola. Isso se deve, geralmente, pela utilização de equipamentos, um móvel pontiagudo ou cortante na sala de aula e o perigo de uma cadeira próxima à janela. A própria estrutura física das salas que pode conter buracos, superfícies lisas, utilização de escadas contínuas ou íngremes, de restos de material de construção abandonado e mato no pátio escolar.

Em função do tempo que os estudantes permanecem na escola e desta ser o ambiente onde desempenham suas interrelações com o meio social, considera-se a instituição como uma "segunda casa” para os alunos. Assim, é valido ressaltar o 
compromisso e a responsabilidade que a instituição tem pelo que acontece aos alunos quando estão na escola. Ademais, os professores são os mais próximos dos alunos e, desse modo, são os maiores responsáveis pelo o que acontece com os alunos dentro da sala de aula, tendo o dever de prestar os primeiros socorros e encaminhá-los para um serviço de saúde (Cabral \& Oliveira, 2019). Dessa forma, torna-se essencial que os educadores estejam capacitados a agir frente às situações que exijam cuidados imediatos, a fim de evitar maiores complicações à saúde dos seus alunos e honrar o compromisso com os pais (Leite et al., 2013).

Pagel, Campos e Batitucci (2015) afirmaram que as práticas simuladas podem ajudar no processo de interação, na apropriação e no desenvolvimento de conceitos científicos, além de permitir que os alunos aprendam como abordar objetivamente o seu mundo e como desenvolver soluções para problemas complexos.

É notório que a realização do curso de primeiros socorros teve um grande interesse já que os alunos acreditam que a educação em saúde é um agente que possibilita a prevenção dos acidentes e o aumento do conhecimento científico.

\section{Considerações Finais}

A escola deveria oferecer a todos um ambiente seguro, procurando reduzir ao máximo os riscos de acidentes. Dessa forma, diante dos mais variados problemas estruturais enfrentados em alguns ambientes escolares são imprescindível a abordagem de conteúdos voltados aos primeiros socorros.

O ensino de primeiros socorros em sala de aula para estudantes é fundamental, considerando-se que o conhecimento por parte dos alunos de tais informações e práticas pode ser crucial para o socorro de vítimas em situações de emergências, sejam em acidentes ou em qualquer outra circunstância a qual tais entendimentos e procedimentos se façam necessários, dentro ou fora do ambiente escolar. Outrossim, por parte de todos os profissionais atuantes dentro do ambiente escolar é importante estarem preparados para atuar no momento em que se fizer necessária a prestação de cuidados imediatos.

Nesse sentindo, é importante também pontuar a relevância da atuação de órgãos e instituições dos setores de saúde na capacitação de estudantes e profissionais da escola, visando dessa forma dirimir os riscos aos quais esses estão expostos diariamente, assim como foi feito pelo Programa de Educação Tutorial - PET Conexões de Saberes de Imperatriz, que voluntariamente desenvolveu na Escola o projeto de primeiros socorros, com o objetivo de informar e capacitar os alunos com intervenções básicas embasadas no conhecimento técnico científico suprindo a necessidade de realizações de atividades educacionais.

O estudo teve como limitação apenas a avaliação do conhecimento teórico dos estudantes, não sendo avaliadas as habilidades práticas, as quais também são de extrema necessidade para o julgamento das intervenções básicas de primeiros socorros.

Portanto, sugere-se a realização de novas pesquisas que abordem o conhecimento prático e o controle emocional, visando à avaliação completa desse procedimento o qual denota uma importante atitude para salvar vidas.

\section{Agradecimentos}

Ao programa de Educação Tutorial pela orientação durante a pesquisa e financiamento da bolsa dos estudantes nas etapas de escrita do projeto, aplicação da pesquisa e das atividades extensionistas.

\section{Referências}

Almondes, B. (2013). O conteúdo de primeiros socorros nas aulas de educação física para estudantes do ensino médio. Cadernos PDE. Secretaria de Educação do estado do Paraná. 
Research, Society and Development, v. 10, n.7, e15110715465, 2021

(CC BY 4.0) | ISSN 2525-3409 | DOI: http://dx.doi.org/10.33448/rsd-v10i7.15465

Banfai et al. (2017) The yearoffirstaid: effectivenessof a 3-day firstaidprogramme for 7-14-year-old primaryschoolchildren. Jornal de Medicina de Emergência, $34,526-532$.

Bergeron et al. (2007). Primeiros socorros. Atheneu.

Brasil. Ministério da Saúde (2003). Manual de Primeiros Socorros. Fundação Oswaldo Cruz.

Brasil (2012). Projeto de lei nº 1689, 07 de agosto de 2012. Lições de primeiros socorros. Senado.

Cabral, E. V. \& Oliveira, M. D. F. A. (2019). Primeiros socorros na escola: conhecimento dos professores. Revista Práxis, 11(22).

Carvalho, F. F. (2008). Acidentes Infantis: Relatos de Diretores e Professores do Ensino Fundamental e Análise do Material Didático. Dissertação do Curso de Filosofia,Universidade Estadual Paulista, Marília, São Paulo.

De Buck et al. (2015) Evidence-basededucationalpathway for theintegrationoffirstaid training in schoolcurricula. Rev. Resuscitation, 94, 8-22.

Dixe, M.A.C.R. \& Gomes, J.C.R. (2015). Conhecimento da população portuguesa sobre Suporte Básico de Vida e disponibilidade para realizar formação. Ver Esc Enferm USP, 49 (4), 640-649.

Galindo Neto, N. M. et al. (2017). Primeiros socorros na escola: construção e validação de cartilha educativa para professores. Acta paul. enferm., 30 (1), 8793.

Gil A.C. (2002). Como elaborar projetos de Pesquisa. Atlas.

Leite, A.C.Q.B. et al. (2013). Primeiros Socorros Nas Escolas. Extendere, 2 (1),61-70.

Lima, L. L. N. \& Neves Junior, R. (2016). Brigada Estudantil de Prevenção de Acidentes e Primeiros Socorros em Palmas (TO). Rev. bras. educ. med., 40 (2), $310-313$.

Matos, D. O. N., Souza, R.S. \& Alves, S.M. (2016). Inclusão da disciplina de primeiros socorros para alunos do ensino básico. Revista Interdisciplinar, 9(3), 68-178.

Pagel, U. R., Campos, L. M. \& Batitucci, M.C.P. (2015). Metodologias e práticas docentes: uma reflexão acerca da contribuição das aulas práticas no processo de ensino-aprendizagem de biologia. Experiências em Ensino de Ciências, 10 (2), 14-25.

Pereira, A. S. et al. (2018). Metodologia da pesquisa científica. UFSM.

Piantino, C. B., Vanin, A. C., Vieira, M. \& Souza, D. H. I. (2018). Propostas de ações educativas no ambiente escolar como prática de promoção da saúde. Ciência et praxis, 11(21), 107-110.

Silva, D. V., Oliveira, M. R. \& Leonel A. R. A. (2015). Conhecimento de graduandos em enfermagem sobre suporte básico de vida. Revista Baiana de Enfermagem, 29 (2), 125-134.

Silva, L. G. S., Costa, J. B., Furtado, L. G. S., Tavares, J. B. \& Costa, J. L. D. (2017). Primeiros socorros e prevenção de acidentes no ambiente escolar: intervenção em unidade de ensino. Enferm Foco [Internet], 8 (3), 25-29.

Silveira, E. T. \& Moulin, A. F. V. (2006). Socorros de Urgência em Atividades Físicas. Brasil. 